\title{
The Contribution of Course Materials to a Social Justice Agenda: Lessons from a Quantitative Literacy Course for Undergraduate Social Science Students
}

Duncan Mhakure

\author{
Jacob Jaftha \\ Sheena Rughubar-Reddy
}

University of Cape Town, Centre for Higher Education Development

Department: Academic Development Programme

Doi:10.5901/mjss.2014.v5n23p1190

\begin{abstract}
This article examines an 'unstated' belief that as the content of a given Quantitative Literacy course grows progressively more complex, the activities relating to social justice issues will surface at a higher cognitive level than those activities lacking social justice issues of social justice. Through the lens of the cognitive apprenticeship model and by means of a four-domain framework, an analysis was conducted of the contribution of the course materials to strengthening student awareness of social justice issues affecting their society. Results show that the expectation that activities relating to social justice outside the classroom would become more abundant as the course evolved over the semester did not materialise. Nonetheless, results did show that activities, which had a social justice agenda, were rated more highly on a cognitive level, than activities without social justice traits. This suggests that the course could thus still achieve its hidden aim of making students more aware of the societal issues in their communities.
\end{abstract}

Keywords: cognitive apprentice theory; quantitative literacy; traditional apprenticeship model; social justice

\section{Introduction}

Proponents of Quantitative Literacy (QL) argue that conventional mathematics does not adequately prepare students for their personal or vocational lives. QL, in contrast, fosters the types of essential mathematical skills and thinking needed to live a more informed, proactive life (Wiest, Higgins \& Frost, 2007). The QL courses for humanities and law students at the University of Cape Town (UCT) were primarily designed to equip students for the quantitative reasoning demands of their studies in higher education. Given the South African context of teaching in higher education in a post-apartheid South Africa with its associated challenges, we maintain that developing a quantitatively literate student is not just important for creating a more effectively functioning society but that it is also a matter of social justice, preparing individuals to function as informed citizens using quantitative information as a key analytical tool. This involved sensitizing students to the extensive social problems in our country (Frith et al., 2010). Although this is the aim of the intended curriculum, no test to determine explicitly the students' level of sensitizing was conducted as this lay outside the ambit of this study. The teaching of QL has an embedded social justice agenda in that it prepares students to participate in societal change and make them more aware of their environment (Jablonka, 2003), while giving them social capital (Yasukawa, Widin \& Chodkiewicz, 2008) and providing them with "a critical awareness that builds bridges between mathematics and the real world" (Johnston, 2007, p. 54).

The QL courses taught are essentially context driven with the QL embedded in contexts such as Children's Rights in South Africa, prison over-crowding and xenophobia (Frith et al., 2010). Given that QL is taught through contexts with inherent difficulties (such as issues of language and the content of the contexts themselves), the plan of sensitizing students through QL to explicit social problems in our society, for example, issues of social justice is never made visible to students.

An important question is thus: Is there a hidden agenda of social justice in the QL courses for the Faculties of Humanities and Law? This paper forms a part of a larger study, which aims to: (i) understand whether the current structure and presentation of the courses constitute a hidden agenda and, (ii) if so, to explore the nature of this agenda. If a social justice agenda does exist, then QL competencies that foster a critical stance should be observed in the context of social justice (Tutak, Bondy \& Adams, 2011), or at least the courses should seek to contribute to this ideal. This article, 
therefore, reports on the analysis of the structure and presentation of the course materials, to understand whether and how the course materials express and contribute to a social justice agenda, as described in Mhakure, Jaftha \& RughubarReddy (2013).

The authors of this paper are facilitators of the QL course. Given the context-bound nature of QL practice, we promote a single core QL course for operational reasons. This paper focuses on the documentary analysis of the course materials, namely, course notes, tests and examination papers. In an attempt to explain the structure and design of the QL course materials, this study uses the cognitive apprenticeship theory. An exposé of this instructional model within the broader social constructivist paradigm will enable a clearer understanding of both the results and the analysis that unfolds in the study.

\section{Theoretical Landscape}

\subsection{Cognitive apprenticeship theory}

Cognitive apprenticeship has its roots in and is strongly influenced by the traditional apprenticeship model, where learning takes place, as novices and experts interact socially, while emphasising teaching skills in the context of their use (Collins, 2006; Dennen \& Burner, 2007; Wang \& Bonk, 2001). The difference between the two apprenticeship models is that "cognitive apprenticeship emphasizes the solving of real world problems under expert guidance that fosters cognitive and metacognitive skills and processes" (Wang \& Bonk, 2001, p.132), whereas traditional apprenticeship focus on the completion of tasks in the psychomotor domain where the apprentice "owns the problem" of moving on to the acquisition of the next skill (Berryman, 1991). Central to the cognitive apprenticeship in formal education is that students learn to become practitioners - not simply learning about the practice but engaging with real world authentic contexts (Dennen \& Burner, 2007). Proponents of cognitive apprenticeship in formal education argue that it reduces the gap between the skills developed and the knowledge learned in abstract concepts, and the application of these concepts to real world contexts. In the QL course, for example, if the course materials used are not pertinent to the discipline of the students and to the social environments in which the graduates will be employed, then students are likely to struggle with the application of the learned skills. Thus, the cognitive apprenticeship, as an alternative to other conventional approaches to formal education and training, aims to "produce graduates with equal thinking and performance capabilities" (Bockarie, 2002, p.48). In cognitive apprenticeship, therefore, the aim is to give the student the opportunity to generalise the skill, to know when a skill can be applied, and to learn when and how the skill can be transferred to solve unfamiliar problems in many different settings or contexts (Collins, 2006; Collins, Brown \& Holum, 1991; Ertmer \& Cennamo, 1995; Hendricks, 2001). By way of contrast, the underpinnings of cognitive apprenticeship also differ from the school curriculum approach in the sense that the latter places emphasis on the problems that emerge from the textbooks and class presentations, thus depriving the students from exploration and new ideas. In the QL course, there are no prescribed textbooks; hence, the instructional materials comprise excerpts from the media, reports from research, and census data, among others. In addition, assessments generally use excerpts from recent texts, whether from research reports and/or the popular press. Given that the QL course materials are designed and structured to develop the quantitative competencies needed by students studying social sciences, we now examine how the cognitive apprenticeship may be used to explain the structure of the QL course materials.

Cognitive apprenticeship consists of a four-dimensional framework that constitutes a learning environment, namely: content, method, sequencing and sociology (Collins, Brown \& Newman, 1989; Collins, Hawkins \& Carver, 1991). Content in the QL, viz. the course materials, refers to the stated knowledge that permits and encourages individual students to use mathematical and statistical concepts, facts, and procedures to solve authentic real world problems. Method entails ways of promoting the development of QL skills and competencies, such as modelling, coaching, scaffolding, articulation, reflection and exploration. Tasks that use exploration as a method of teaching are intended to encourage students to hypothesise and design solutions for problem solving activities. Sequencing of learning activities encompasses the presentation of problem solving contexts in "an ordering from simple to complex, with increasing diversity and global before local skills" (Wilson \& Cole, 1991, p.53). Sociology suggests that learning tasks should teach knowledge, skills and competencies in real contexts that resemble the manner in which the acquired knowledge, skills and competencies will be used in everyday situations in future.

\subsection{Zone of proximal development}

The zone of proximal development (ZPD) has a huge influence in the conceptualisation of the cognitive apprenticeship 
practice. Arguably the most significant aspect of Vygotsky's work, the ZPD is defined as "the gap or area between actual and potential development" (Ghefaili, 2003, p.4). In other words, the ZPD is the region, which is located just beyond the student's current ability; as the student acquires new skills and competencies through social interactions with more capable peers, experts or facilitators, the ZPD will shift. In these social and cultural interactions, social tools such as language and other sign systems play a key role in the cognitive development and learning of individual students (Bockarie, 2002; Tudge, 1990; Zuengler \& Miller, 2006). Rogoff (1990) argues that cultural learning and development, and cognitive development, are products of learning and teaching within the ZPD. Social interactions, posits Rogoff (1990), create an enabling environment that encourages students to participate in learning activities, such as those in the QL course that would not have been accessible to them independently and outside the course. Therefore, we can conclude that cognitive apprenticeship learning takes place in the ZPD and that the ZPD is an important factor to consider when scaffolding QL learning activities (Bean \& Stevens, 2002; Rogoff \& Wertsch, 1984). Scaffolding, according to Rasmussen (2001, p.570) is "a form of support for the development and learning of children and young people". The importance of scaffolding is twofold: firstly, it cognitively foregrounds a variety of activities, such as hints, models, analogies and demonstrations among others, which allow students to carry out selected tasks successfully; secondly, emotionally, scaffolding shields the students from experiencing emotions of failure during problem solving activities by providing students with the necessary support and tools, such as hints that will allow them to engage successfully with the QL contexts. The description we have advanced here is usually referred to as static scaffolding - which is a paperbased general account. However, caution is advised when scaffolding activities to ensure that they are tailored to suit the learning group's needs (Molenaar, Roda, Van Boxtel \& Sleengers, 2011).

\section{Social Justice within the Context of the Study}

According to the Constitution of South Africa, human rights are those basic and fundamental rights to which every human being is entitled. These rights are absolute, and they cannot be taken away. The Bill of Rights, "a cornerstone of democracy in South Africa", "enshrines the rights of all people in our country and affirms the democratic values of human dignity, equality and freedom" (Chapter 2, Constitution of South Africa). The values and rights protected in the South African Constitution and the Bill of Rights resonate in UCT's mission statement, which aims to produce graduates whose qualifications are underpinned by values of engaged citizenship and social justice and to provide "a superior quality educational experience for undergraduate and postgraduate students through supporting programmes that stimulate the social consciousness of students" (see - http://www.uct.ac.za/about/intro/our mission). These are further supported by the Statement of Values for UCT.

The Bill of Rights advocates that every child has the right to family care, basic nutrition, shelter, basic health care services and social services, and to be protected from maltreatment and abuse. The UCT mission statement further echoes the rights of children through the vision and mission of the Children's Institute (based at the University of Cape Town). The Children's Institute promotes a society in which children are valued, nurtured and protected, their rights are realised, and "they are able to participate, develop and reach their full potential"; it thus aims to "contribute to policies, laws and interventions that promote equality and realise the rights and improve the conditions of all children in South Africa ..." (see - http://www. ci.org.za).

In keeping with UCT's aim to produce graduates whose qualifications are supported by values of engaged citizenship and social justice and to stimulate the social consciousness of students, the QL courses taught by UCT are embedded in contexts such as Children's Rights in South Africa. In an attempt to probe students' understanding and awareness, as well as their belief in their agency on issues of social justice, they were presented with two scenarios, namely, a service delivery protest scene on television and a poster advertising a debate on employment equity and affirmative action. Although the materials analysed in this study were used by both humanities and law students, the study focussed on the students in humanities only. Hence humanities students were asked to participate in the survey after they had completed the lectures in their course. The question we need to ask is: what are the current views of the social science students on issues of social justice? It must be remembered that this paper forms a part of a larger study that examines the formulation and application of a framework to analyse QL course materials. Nonetheless, we feel that a brief survey of the social justice agencies of humanities students will provide insights into what types of students are being targeted by these course materials. In the survey, students were asked to give their responses on a Likert Scale, with positive on one end represented by a 1 , and negative on the other end represented by a 5 . There were two scenarios, namely: Scenario 1 - students' opinions while watching a protest march on television; Scenario 2 - students' opinions on participating on a debate being advertised on campus on employment equity and affirmative action. The averages for all the scores of questions in each of the scenarios were calculated. 
The results from the survey indicated that large proportions of students remained "neutral" on issues: some questions received as many as 50\% neutral responses, with some respondents having neutral responses to as many as 23 out of 34 questions (i.e. 68\%). Many respondents were generally negative about their willingness to participate in the protest march, or the debate (the mean score ranged from 2.69 to 3.72, where neutral was 2.50 and above was negative) or largely neutral $(31 \%-52 \%)$. Regarding the legitimacy of participating in the protest march and/or debate, the students' responses were generally positive (their scores ranged from 0.83 to 2.22 ). Students were quite neutral in their responses to 'self-driven' - these are situations that require the students to initiate a protest march. The scores on the latter were ranging between 2.39 and 2.67. Instead, the scores were fairly positive in response to 'agency: external' - here students did not mind participating as long as someone else organised the protest (obtaining scores between 1.28 and 2.67).

A question that begs to be asked is: Does it make sense to expose this class to a QL course with a 'hidden' social justice agenda or should social justice issues be made more explicit in the course materials?

\section{The Framework}

\subsection{Development of the framework}

In this section, we summarise the framework that was developed and validated by Mhakure et al. (2013). We also demonstrate how the framework was operationalized and applied to selected QL course materials by using an example from a QL teaching and learning context. The framework is divided into four domains, namely: course content, expected QL competencies, Bloom's taxonomy levels, and social justice agenda.

Table 1: Summary of the framework

\begin{tabular}{llll}
\hline \hline Course content & Expected QL competencies & Bloom's taxonomy levels & Social justice agenda \\
\hline \hline Number sense and & Comparing numbers & Remembering & SJ not explicit in both context and \\
representation & Reading from charts, tables, figures and texts & Understanding & question \\
Proportions & SJ beyond classroom & Applying & SJ explicit in one of them \\
Statistical data representation & Procedural competencies & Analysing & SJ explicit in both context and \\
Compound growth & Writing skills & Evaluating & question \\
Everyday personal finance & Data representation methods & Creating & \\
& Critical thinking skills & & \\
\hline \hline
\end{tabular}

Source: Adapted from Mhakure et al. $(2013$, p.395)

This framework supports and utilises the cognitive apprenticeship theory, the aim of which is to "address the problem of inert knowledge and to make the thinking of a learning activity visible to both the student and the teacher" (Ghefaili, 2003, p.1). In addition, as was already alluded to in the four-dimensional framework of the cognitive apprenticeship, the framework allows the students the opportunities to acquire and "generalise the skill, [to] know when a skill can be applied and that the skill can be transferred to solve unfamiliar problems in many different settings or contexts" (Mhakure et al., 2013, p.392). The latter contexts are foregrounded in social justice issues, where knowledge construction takes place when students are working in communities of practice.

\subsection{Operationalizing the framework}

The following excerpt from Statistics South Africa 2006 is used as an example to demonstrate how the framework was applied to the QL course materials. This excerpt represents the type of QL course material context the students are exposed to during teaching and learning. Students are expected to unpack both the statistical and mathematical concepts embedded in these contexts; more specifically, in this case, students are also expected to juxtapose the concepts given in the text with the ones in the table. It is critical that students realise this is a real world context and that much of what the context is about - viz. with regard to child mortality rates - is real and part of the social challenges from the communities, where the students reside. These child mortality rates are thus part of the social justice issues underlying this course. We have already stated that this study is about a QL course designed for humanities/social science students - in other words, for students studying psychology and social work degree programmes. The context described here represents a case of situated learning, whose critical tenet is to have students carry out tasks and solve diverse problems that mirror the multiple practical uses of their acquired knowledge in the future, for example, work actually done by students when they become social workers (Cobb \& Bowers, 1999; Ghefaili, 2003; Orgill, 2007; Rogoff, 1990). 


\title{
4.3 An example of a QL context from the course material
}

\begin{abstract}
Child Health: The general context by Beverly Draper \& Johannes John-Langba. The World Health Organisation describes the infant mortality rate (IMR) and the under-five mortality rate (U5MR) as the leading indicators of the level of child health in a country. The IMR indicates the number of children per 1000 live births who died before their first birthday. The U5MR is the number of deaths among children before reaching the age of 5 per 1000 live birth.
\end{abstract}

Table: The infant mortality rate and the under-five mortality rate of South Africa in 2001-2005

Deaths per 1000 per live births

\begin{tabular}{cccccc}
\hline & 2001 & 2002 & 2003 & 2004 & $2005^{*}$ \\
$\begin{array}{c}\text { Infant mortality rate } \\
\begin{array}{c}\text { Under-five mortality } \\
\text { rate }\end{array}\end{array}$ & 28.8 & 33.1 & 36.5 & 38.1 & 43.0 \\
\hline
\end{tabular}

"2005 data are based on the mid-year estimates. Source: Statistics South Africa (2006). Mortality and causes of death in South Africa, 2003 and 2004: Findings from death notification; Statistics South Africa (2005) Mid-year estimates 2005. In P. Ijumba \& A. Padarath (Eds) (2006) South African Health Review 2006. Durban: Health Systems Trust. Available statistics rely on the number of births and deaths that are actually registered, and under-registration of births and deaths remains a challenge to the production of reliable data on infant and child mortality.

\section{Questions}

1. If there were approximately 47300 infants who died before their first birthday in 2005 , how many live births were there in that year?

2. According to a publication of the United Nations Organisation, World Population Prospects: 2006 Revision, the IMR for South Africa in 2006 was 44.8 per 1,000 live births, whereas for Botswana it was 46.5. Does this mean that in 2006 there were more infants less than 1 year old who died in Botswana than in South Africa? Explain.

\section{Figure 1: Example of a QL context with questions}

During teaching and learning of the QL course, students in lecture groups are transformed into communities of practice; essentially, students work through the QL course material activities in small groups, where individuals within the group ask questions, define and share their understanding of the material. Each group is then mandated to give feedback on their discussions to the rest of the lecture group. Anecdotally, it was found that students find this type of pedagogy involving communities of practice - very difficult to practice, since it is a departure from their individualistically driven high school pedagogy (Bielaczyc \& Collins, 1999; Lave \& Wenger, 1991; Wenger, 1998). A typical QL context is illustrated in Figure 1, these contexts usually have different social themes.

The context illustrated in Figure 1 has a social justice agenda in that we note that the mortality rates for both categories - infant mortality and under-five mortality - nearly doubled over a five-year period. Unless something drastically happens, the millennium goal of reducing the infant mortality rate by two thirds by 2015 from the 1990 figure of 45 is not within reach. This conclusion should surely raise concerns, given that the right to proper health care is enshrined in the Constitution of South Africa. In fact, it could be argued that, with the proper health policies and government accountability, the millennium goal could still be realised. 
Table 2: Applying the framework to the context and the questions

\begin{tabular}{lllll}
\multicolumn{1}{c}{ Question } & \multicolumn{3}{c}{ The Framework } \\
\hline \hline & $\begin{array}{c}\text { Course } \\
\text { content }\end{array}$ & $\begin{array}{c}\text { QL } \\
\text { Competency }\end{array}$ & $\begin{array}{c}\text { Bloom's } \\
\text { cognitive } \\
\text { level }\end{array}$ & $\begin{array}{c}\text { Social } \\
\text { justice } \\
\text { agenda }\end{array}$ \\
\hline \hline $\begin{array}{l}\text { 1. If there were approximately } 47300 \text { infants who died before } \\
\text { their first birthday in 2005, how many live births were there } \\
\text { in that year? }\end{array}$ & Proportions & $\begin{array}{c}\text { Procedural } \\
\text { competencies }\end{array}$ & $\begin{array}{c}\text { Social justice } \\
\text { explicit in } \\
\text { context only }\end{array}$ \\
$\begin{array}{l}\text { 2. According to a publication of the United Nations } \\
\text { Organisation, World Population Prospects: 2006 Revision, } \\
\text { the IMR for South Africa in 2006 was 44.8 per 1,000 live } \\
\text { births, whereas for Botswana it was 46.5. Does this mean } \\
\text { that in 2006 there were more infants less than 1 year old, } \\
\text { who died in Botswana than in South Africa? Explain. }\end{array}$ & Proportions & $\begin{array}{c}\text { Comparing } \\
\text { numbers }\end{array}$ & Analysing & $\begin{array}{c}\text { Social justice } \\
\text { explicit in } \\
\text { context and } \\
\text { question }\end{array}$ \\
\hline \hline
\end{tabular}

All contexts in the QL course materials require students to engage in specific activities in the form of questions or tasks. In this context, the two questions that were asked as part of the course material (see Table 2) were used in the study to illustrate how the framework was operationalized. Question 1 requires students to determine the total number of live births, given a number that is a fraction of that total. In terms of content, they are thus required to have an understanding of proportions, and the QL competency expected is procedural in nature, requiring a formula or at least formulaic reasoning. Given that the QL competency requires the application of a formula, we rate the question at the applying level on Bloom's taxonomy. The Children's Rights context, which forms a part of the course material, has social justice embedded in it. As the question does not explicitly ask the reader to consider the Bill of Rights issues, social justice is not embedded in the question: social justice is thus explicit in the context only.

A similar analysis was applied to Question 2: here, too, the content was also about proportions; the QL competency involved comparing numbers and Bloom's taxonomy level was analysing (viz. infant deaths between South Africa and Botswana), making the issue of social justice explicit in context and question. The latter method of analysis was applied to selected learning activities of the QL course material units in addition to the questions in Assessment 1 and the examination.

The following section will discuss the findings from the study.

\section{Findings}

Frequency distributions were obtained by applying the framework to the course materials and the assessments in 2012, where each question and/or activity was catalogued in terms of its attributes in the four dimensions. The distributions obtained were used to test or confirm several unspoken assumptions and beliefs, namely: that the first unit would be easier than the rest of the course and that the work would become progressively more complex; that the activities involving social justice issues were at a higher level and more complex than those not involving social justice; and that the expected activities involving social justice beyond the classroom would become more abundant later in the course.

Distributions were compared by using the chi-squared test on expected frequencies, and residual $p$-values were used where significant differences were observed. The application of the framework suggests that questions on the lower scale of complexity as measured on Bloom's taxonomy were favoured in the distribution of questions with no social justice content, as compared to the distribution of questions with social justice content ( $p$-value 0.0000266 ), which was as expected.

The application of the framework confirms the designed difference between unit 1 (Children's rights in South Africa) and the rest of the materials on the mathematical content axis. However, it was found that the category "social justice beyond the classroom" type of questions/activities were much less emphasised in course materials than they had been in unit 1, contrary to expectations ( $p$-value 0.00473). Also, unit 1 seems to be asking more of the students, as questions on the lower level of Bloom's taxonomy were much more abundant in the course materials than they had been in unit 1 ( $p$-value 0 - more than 7 standard deviations difference). Again, this is contrary to what we were expecting.

The application of the framework confirms that the examination is not statistically different from the course materials in terms of the complexity of the questions/activities, as measured on Bloom's taxonomy, but does indicates that the procedural competencies category is favoured more in the examination than it is in the course materials ( $p$-value $0.0020)$. 


\section{Conclusions}

A naive application of the framework will not capture the temporal dimension of the cognitive apprenticeship model, which we use as a lens to view the contribution of the course materials in our attempt to make students more conscious of issues of social justice in society. A nuanced view of the framework, which considers that the course materials are used in a linear fashion could provide insight into the temporal aspect.

By applying cognitive apprenticeship model, especially the ZPD aspect, we hope to see a shift in the social justice expectation (especially beyond the classroom) as well as increasing complexity in the tasks assigned as the semester progressed. The application of the framework to the different parts of the materials would provide evidence of the contribution to the goal.

It was found that the category social justice beyond the classroom is emphasised less in the remaining course materials than it is in the first unit, and thus the contribution of the material in deepening the students' awareness of social justice issues affecting their society cannot be based on this data. This is also borne out by the observation that course material in the first unit is statistically more demanding than the rest of the materials, as measured on Bloom's taxonomy scale.

It should be noted, however, that the course materials is not the 'learned curriculum' (viz. all that the students learn and experience in this course) and that the way in which the course is experienced could offset the negligible contribution of the course materials to the goal. The point here is that even though the course materials do not explicitly teach social justice issues, the way the course is taught, and the practical lessons given by the teachers, could nonetheless make students more conscious of such issues. The course could thus still achieve its implicit aim of making students appreciative of the societal issues in their communities, especially since it was found that activities involving social justice aspects are rated on a higher cognitive level than those not involving social justice aspects. It was noted in Frith et al. (2010) that students had difficulty with the course (materials) and with distinguishing the context from the content; such difficulties, of students struggling to come to grips with this dilemma provides ample experiential learning with regard to societal issues.

\section{References}

Bean, T. W., \& Stevens, L. 2002. Scaffolding reflection for pre-service and in-service teachers. Reflective Practice, 3 (2), 205-218.

Berryman, S. E. 1991. Designing effective learning environments: Cognitive apprenticeship models. New York: Columbia University. (ERIC Document Service No. ED 337 689).

Bielaczyc, K., \& Collins, A. 1999. Learning communities in the classrooms: A reconceptualization of education practice. In C. M. Reigeluth ( $\mathrm{Ed})$, Instructional-design theories and models: A new paradigm of instructional theory (pp. 296-292). Place of publication: Publisher. Routledge.

Bockarie, A. 2002. The potential of Vygotsky's contributions to our understanding of cognitive apprenticeship as a process of development in adult vocational education. Journal of Career and Technical Education, 19 (1), 47-66.

Children's Institute, $h$ ttp://www.ci.org.za.

Cobb, P., \& Bowers, J. 1999. Cognitive and Situated Learning Perspectives in Theory and Practice. Educational Researcher, 28 (2), 415.

Collins, A. 2006. Cognitive Apprenticeship. In R. K. Sawyer (Ed), The Cambridge Handbook of the learning Sciences. Cambridge University Press.

Collins, A., Brown, J. S., \& Holum, A. 1991. Cognitive Apprenticeship: Making thinking visible. American Educator, 15 (3), 6-11.

Collins, A., Brown, J. S., \& Newman, S. E. 1989. Cognitive apprenticeship: Teaching the craft of reading, writing, and mathematics. In L. B. Resnick (Ed), Knowing learning, and instruction: Essays in honour of Robert Glaser (pp. 453-494). Hillsdale, NJ: Lawrence Erlbaum Associates.

Collins, A., Hawkins, J., \& Carver, S. M. 1991. A cognitive apprenticeship for disadvantaged students. In B. Means, C. Chelemer \& M. S. Knapp (Eds), Teaching advanced skills to at risk students (pp. 216-243). San Francisco: Jossey-Bass.

Dennen, V. P., \& Burner, K. J. 2007. Cognitive Apprenticeship in Educational Practice: Research on Scaffolding, modelling, mentoring, and coaching as instructional strategies. In D. H. Jonassen, M. J. Spector, M. Driscoll, M. D. Merrill, J. van Merrienboer (Eds.). Handbook of research for educational communications and technology (3nd Ed.) (pp. 426-437). Hillsdale, NJ: Erlbaum.

Ertmer, P. A., \& Cennamo, K. S. 1995. Teaching Instructional Design: An Apprenticeship Model. Performance Improvement Quarterly, 8 (4), 43-58.

Frith, V., Le Roux, K., Lloyd, P., Jaftha, J., Mhakure, D., \& Rughubar-Reddy, S. 2010. Tensions between Context and Content in a Quantitative Literacy course at University. In U. Gellert, E. Jablonka \& C. Morgan (Eds.), Proceedings of the Sixth International Mathematics Education and Society Conference (pp.259-269). Berlin: Freie Universität Berlin.

Ghefaili, A. 2003. Cognitive Apprenticeship, Technology, and Contextualisation of Learning Environments. Journal of Educational Computing, Design and Online Learning, 4, 1-27. 
Hendricks, C. C. 2001. Teaching Casual Reasoning through Cognitive Apprenticeship: What are the results from situated learning? The Journal of Educational Research, 94 (5), 302-311.

Jablonka, E. 2003. Mathematical Literacy. In A. J. Bishop, M. A. Clements, C. Keitel, J. Kilpatrick, \& F. K. S. Leung (Eds.), Second International Handbook of Mathematics Education (pp.75-102). Dordrecht: Kluwer Academic Publishers.

Johnston, B. 2007. Critical numeracy? In S. Kelly, B. Johnston, \& K. Yasukawa (Eds), The Adult Numeracy Handbook: Reframing adult numeracy in Australia (pp. 50-56). Sydney, NSW: Adult Literacy and Numeracy Australian Research Consortium.

Lave, J., \& Wenger, E. 1991. Situated learning: Legitimate peripheral participation. New York: Cambridge University Press.

Mhakure, D., Jaftha, J., \& Rughubar-Reddy, S. 2013. A framework to understanding the contribution of Quantitative Literacy to the social justice agenda: A pilot study. Proceedings of the Seventh International Mathematics Education and Society Conference, $2^{\text {nd }}-7^{\text {th }}$ April 2013, pp. 390-399, Cape Town, South Africa.

Molenaar, I., Roda, C., Van Boxtel, C. \& Sleengers, P. 2012. Dynamic scaffolding of socially regulated learning in a computer-based learning environment. Computer and Education, 59 (2), 515-523.

Orgill, M. 2007. Situated cognition. In G. M. Bodner \& M. Orgill. Theoretical Frameworks for research in Chemistry/Science Education. Pearson Education Inc., NJ.

Rasmussen, J. 2001. The Importance of Communication in Teaching: A Systems-Theory Approach to the Scaffolding Metaphor. Curriculum Studies, 33 (5), 569-582.

Rogoff, B. 1990. Apprenticeship in thinking: Cognitive development in social context. New York: Oxford University Press.

Rogoff, B., \& Wertsch, J. V. 1984. Children's learning in the "zone of proximal development". San Francisco: Jossy-Bass.

Tudge, J. 1990. Vygotsky, the zone of proximal development, and peer collaboration: Implications for classroom practice. In C. C. Moll (Ed). Vygotsky and education. Instructional applications of sociohistorical psychology. (pp. 155-172). New York. Cambridge University Press.

Tutak, F. A., Bondy, E., \& Adams, A. L. 2011. Critical pedagogy for critical mathematics education. International Journal of Mathematical Education in Science and Technology, 42:1, 65-74, DOI: 10.1080/0020739X.2010.510221.

University of Cape Town, http://www.uct.ac.za/about/intro/our mission.

Wang, F., \& Bonk, C. J. 2001. A Design Framework for Electronic Cognitive Apprenticeship. Journal of Asynchronous Learning Networks, 5(2), 131-151.

Wenger, E. 1998. Communities of practice: Learning, meaning, and identity. New York: Cambridge Press.

Wiest, L. R., Higgins, H. J., \& Frost, J. H. 2007. Quantitative Literacy for Social Justice. Equity and Excellence in Education, 40, 47-55.

Wilson, B. \& Cole, P. 1991. A Review of Cognitive Teaching Models. Educational Technology Research and Development, 39 (4), $47-64$.

Yasukawa, K., Widin, J., \& Chodkiewicz, A. 2008. The benefits of adults learning numeracy. In J. F. Matos, P. Valero, \& K. Yasukawa (Eds.), Proceedings of the 5th International MES Conference (pp.495-504). Lisbon: Universidade de Lisbon, Aalborg University.

Zuengler, J., \& Miller, E. R. 2006. Cognitive and Social-cultural Perspectives: Two parallel SLA worlds? TESOL Quarterly, 40 (1), 35-58. 